\title{
Associations of out of school physical activity, sedentary lifestyle and socioeconomic status with weight status and adiposity of Cameroon children
}

Lifoter K. Navti ${ }^{1,2^{*}}$, Mary B. Atanga ${ }^{3}$ and Loveline L. Niba ${ }^{1,2}$

\begin{abstract}
Background: Low physical activity and a sedentary lifestyle are contributing to overweight/obesity in children. This study aims to explore relationships between out of school physical activity, sedentary lifestyle and socioeconomic status indicators with children's weight status and adiposity.

Methods: Five hundred twenty-two children of ages 5 to 12 years were randomly selected in a school-based cross sectional study in Bamenda, Cameroon. Weight and height were measured and BMI calculated. These variables were standardized for age and gender. Socioeconomic variables and proxy measures of physical activity and sedentary lifestyle of children were reported by parents using a structured questionnaire. Bivariate and multivariable logistic regression was used to calculate odds ratios.

Quantile regression was used to compare median values of triceps skinfold thickness across the different factors.

Results: In bivariate analysis, physical activity $>4-7$ times/week was significantly $(p=0.010)$ associated with a lower prevalence (5.9\%) of overweight/obesity. In multivariable analysis, physical activity $>$ twice a week (OR 0.1, 95\% Cl $0.05-0.3$ ), sedentary lifestyle $>3 \mathrm{~h}$ /day (OR 2.4, 95\% Cl 1.2 - 4.3) and being in the high occupation class (OR 4.3, 95\% Cl $2.2-8.1)$ independently predicted overweight/obesity. With quantile regression, physical activity $>4-7$ times/week was significantly $(p=0.023)$ associated with a $1.36 \mathrm{~mm}$ decrease in median triceps skinfold thickness, while sedentary lifestyle ( $>3 \mathrm{~h} /$ day) $(p=0.026)$ and being in the high occupation class $(p=0.007)$ were significantly associated with a $1.37 \mathrm{~mm}$ and $1.86 \mathrm{~mm}$ increase in median triceps skinfold thickness respectively.

Conclusion: Physical activity is inversely related to BMI-defined overweight/obesity and triceps skinfold thickness. Also, a high sedentary lifestyle and a high occupation class were associated with overweight/obesity and had the largest significant relationship with triceps skinfold thickness. There is need to objectively assess physical activity and sedentary lifestyle in our setting, in and out of school. Also longitudinal studies are warranted to understand the influence of cultural and behavioral drivers of physical activity and sedentary lifestyle.
\end{abstract}

Keywords: Physical activity, Sedentary lifestyle, Overweight/obesity, Triceps skinfold thickness, Quantile regression

\footnotetext{
* Correspondence: knavti@gmail.com

'Department of Biochemistry, Catholic University of Cameroon (CATUC),

Bamenda, P.O. Box 782, Bamenda, Cameroon

${ }^{2}$ Nutrition and Health Research Group (NHRG), Bamenda, Cameroon

Full list of author information is available at the end of the article
} 


\section{Background}

Overweight/obesity is affecting children in both developed and developing countries and had been described as a global threat to health more than a decade ago [1] It affects approximately one-tenth of school-age children globally [2]. Increasing numbers in overweight/obese children have been recorded in developing countries undergoing an epidemiologic transition [3, 4], which is characterized by adoption of a sedentary lifestyle, physical inactivity, changes in dietary habits, rapid urbanization and better income [5-7].

Physical activity influences energy balance and has been shown to be beneficial to the health of school-age children $[8,9]$, with the likelihood of the children becoming more active in adulthood [10]. For instance, a follow-up study among US children between the ages of 10 and 15 years by Berkey et al. [11] revealed that when activity increased, BMI dropped. Also, lower levels of exercise has been shown to be associated with increased child adiposity $[12,13]$. Despite the documented benefits of physical activity, evidence relating physical activity and overweight/obesity has not been consistent even in cohort studies, which indicated either weak or no associations between physical activity and overweight/obesity in children $[14,15]$.

Leisure time activities in children have changed over the past years as a result of advances in technology. In Cameroon, there is no documented evidence on leisure time activities in children. However, evidence from other countries indicate that children spend more time in sedentary activities like watching $\mathrm{TV}$, internet and playing video games [16]. A report revealed that TV watching and playing of video games are common among younger children, while internet activities are common among adolescents, and a high proportion (> 80\%) of the children spend on average, one and a half hours a day watching TV [17]. This is concerning because a recent study indicated that the use of electronic media has been associated with childhood overweight/obesity in schoolage children [18]. However, an Australian study did not find such associations among adolescents [19].

In some African countries, less than half of children and youths meet up with the WHO daily requirement of $60 \mathrm{~min}$ of moderate-to-vigorous intensity physical activity [20]. Also, a study in Senegal indicated that adolescents occupy themselves with sedentary activities for half of their time [21]. The opportunities for physical activity are influenced by socioeconomic, cultural and even geographical factors, which contribute to differences in the numbers of individuals affected with overweight/obesity. For instance, a recent report in rural South Africa indicated that sedentary time and physical activity were independently predicted by socioeconomic status (SES) [22]. Other, studies had revealed that subjects from urban settings were least active compared to their rural peers $[23,24]$ and low physical activity level was associated with attending a private school [25]. However, most of these studies used body mass index (BMI), which does not directly reflect adiposity levels [26, 27].

The primary goal of this study is to investigate the contribution of selected factors (out of school physical activity, out of school sedentary lifestyle and SES indicators) to children's weight status and adiposity, using body mass index and triceps skinfold thickness respectively.

\section{Methods \\ Subjects}

This school-based cross sectional analysis included a randomly selected sample of children ( 5 - 12 years) from 6 primary schools in Mezam Division of the North West Region (NWR) of Cameroon. A list of both private and public primary schools in Mezam Division of the NWR was obtained from the North West regional delegation for basic education. In order to have an adequate mix of socioeconomic groups and taking into consideration the distribution of more schools in urban than rural settings, 4 schools in the urban (2 private, 2 public) and 2 schools in the rural (1 private, 1 public) settings were randomly selected and contacted. Any school that refused to participate was replaced by another randomly selected one on the list. Based on the presumption that each class in schools should have a maximum of 40 - 45 children, 20 children were randomly selected from the 6 classes in each school. This was done to maximize the age distribution of the sample. A total of 720 children were randomly selected. Consent information which included the objectives of the study and also the study questionnaire were sent to parents/guardians through their children. The consent information was also given to the head teachers of the different schools. 609 questionnaires were returned giving a response rate of $84.6 \%$. In addition, 87 participants were dropped because of missing data on physical activity, sedentary lifestyle and some SES indicators. However, there were no significant differences in anthropometric variables between those dropped and those retained in the study. A final sample of 522 children (262 boys and 260 girls) was included in the analysis.

\section{Ethical considerations}

Ethical approval for this study was obtained from the institutional review board of the Catholic University of Cameroon (CATUC), Bamenda. Administrative clearances were obtained from the North West regional delegations for basic education and public health. All head teachers and parents/guardians gave written informed consent before the study commenced. Verbal assent was also obtained from each child before any study related procedure was carried out. 


\section{Data collection}

\section{Anthropometry}

All measurement activities were carried out by trained nurses using standardized protocol while children were in school during morning hours. Body weight, to the nearest $0.1 \mathrm{~kg}$ of the children was obtained using a portable digital scale (Omron BF 511, Japan) in light clothing and without shoes. Height was measured to the nearest $0.1 \mathrm{~cm}$ using a portable stadiometer (Seca 213, Germany) without shoes. BMI, in $\mathrm{kg} / \mathrm{m}^{2}$ was calculated from weight and height and used as a measure of the weight status of participants. Triceps skinfold thickness was measured half-way down and parallel to the long axis of the flexed left arm (between the acromion and olecranon) hanging on the child's side using a standard skinfold caliper (Holtain Ltd., Croswell, Crymch, UK) to the nearest $0.2 \mathrm{~mm}$ that functioned under a constant pressure of $10 \mathrm{~g} / \mathrm{mm}^{2}$ [28]. The skinfold measurements were carried out in triplicates by one observer (LKN) and the average value was recorded and used as a measure of adiposity. The children's dates of birth and gender were obtained from school records during anthropometric measurements.

The information on school type (private or public) was obtained from the school administration.

\section{Parent/guardian questionnaire}

Information on the children's socioeconomic background, physical activity and sedentary lifestyle were reported by parents/guardians using a pre-tested questionnaire. This questionnaire was established in both English and French. In the absence of a validated instrument to assess activity levels of school-age children in our setting, the established physical activity and sedentary lifestyle components of our questionnaire were similar to that of a previous study in Pakistan [29]. However, no validity test was carried out. We adapted the questionnaire used in Pakistan in two ways. Firstly, instead of asking participants to indicate the frequency of participation in physical activity and sedentary lifestyle, our questionnaire provided categories of frequency of participation in both activities for participants to choose. Secondly, a sports activity that is not common among school children in our setting, like playing cricket, was substituted with football, which also involve physical movement.

The parents/guardians reported the out of school physical activity levels/sedentary lifestyle of their children and also provided information on their socioeconomic background (monthly income, professions and level of education) as explained below:

\section{Out of school physical activity}

In this study, out of school physical activities included the following; farm work, household chores, ball dodging, hopscotch, skipping rope, hide and seek, dancing, football, handball, jogging, tennis, cycling, play on the playground and walking to school. The parents selected the frequency of the children's involvement in each of the above activities in a week (Monday to Friday and Saturday to Sunday) [30] from the following categories: (i) one time/week, (ii) 2 times/week, (iii) 3 times/week, (iv) 4 times/week, (v) 5 times/week, (vi) 6 times/week and (vii) 7 times/week. The average of the number of times involved in all the activities was calculated and used to assign the children into the following groups; low ( $\leq 2$ times/week), moderate $(>2-4$ times/week) and high (> $4-7$ times/week) physical activity.

\section{Out of school sedentary lifestyle}

The out of school sedentary lifestyle of the children included; playing board games/cards, playing video games, reading/doing homework, watching TV, using the computer (internet), listening to music and motorization to school. The parents also selected the number of hours their children spend in the above activities during weekdays and weekend days from the following categories: (i) one hour/day, (ii) $2 \mathrm{~h} /$ day, (iii) $3 \mathrm{~h} /$ day, (iv) $4 \mathrm{~h} /$ day, (v) $5 \mathrm{~h} /$ day and (vi) $6 \mathrm{~h} /$ day. The mean time (in hours/day) [31] spent on all the activities was calculated and used to stratify participants as follows; low ( $\leq 1 \mathrm{~h}$ /day), moderate ( $>1-3 \mathrm{~h} /$ day) and high (>3 $-6 \mathrm{~h} /$ day) sedentary lifestyle.

No significant differences were observed in physical activity and sedentary lifestyle between weekdays and the weekend days.

\section{Socioeconomic status indicators}

Occupation class: Parents/guardians were asked to provide information on their monthly income and professions. The Cameroon public service classification system of civil servants based on income and profession was used to determine the occupation class of the parents. The civil servant categories A, B and C were used to classify parents/guardians into the high, middle and low occupation classes respectively [32]. Each child was designated to the parent in the highest occupational class.

Education level: The education level of parents was also obtained from the questionnaire and they were categorized as follows; illiterate, primary, secondary and higher education after having spent none, $\leq 6$ years, 7 to 13 years, and $>13$ years of education respectively. The parent with the highest level of education was used to assign the children to the appropriate education group.

\section{Statistical analysis}

The distribution of continuous variables was assessed using the Kolmogorov-Smirnov (K-S) test. Z-scores for 
weight, height and BMI were calculated using WHO AnthroPlus software, which utilizes the WHO 2007 growth reference data for children of ages 5 to 19 years [33]. A descriptive analysis was performed and values reported as mean (minimum - maximum) for continuous variables and proportions for categorized variables. Also, a parametric independent samples $t$-test and non-parametric Mann-Whitney $U$ test were used to compare means of anthropometric variables between boys and girls, and proportions were compared using Chi square test.

Odds ratios, reported with their corresponding 95\% confidence intervals for weight status (overweight/obesity), were calculated using bivariate and multivariable binary logistic regression models. The bivariate analysis included models which assessed the relationship between each factor and weight status. In multivariable analysis, odds ratios were adjusted for age, gender, design variables (school and class) and all the factors that were significant in the bivariate analysis. The design variables were included in the model in order to avoid violating the assumption of independence.

In addition, unadjusted analysis was carried out using the Kruskal-Wallis test to compare the median triceps skinfold thickness across the different factors. Further, the median triceps skinfold thickness across the different factors were adjusted using multiple quantile regression analysis. Quantile regression was used because it assesses the relationship across the distribution and the assumption of normality is not a requirement. The Powell Kernel approach for estimating standard errors [34] was used to calculate the regression estimates of the median of triceps skinfold thickness. The quantile regression analysis included all variables in the unadjusted analysis. The WHO criteria was used to define overweight (BMI z-score $>+1$ ) and obesity (BMI z-score $>+2$ ) [33] and statistical significance was considered at $p<0.05$ level. The statistical software, $R$ version 3.4.1 with QUANTREG package installed [34] was used for all statistical procedures.

\section{Results}

The overall prevalence of overweight/obesity among the children in this study was $18.0 \%$. When overweight and obesity were combined, more boys were affected than girls. However, this difference was not significant $(p=0.131)$ (Table 1). On the basis of the type of school attended, there was no significant difference in prevalence of overweight/ obesity between children attending private schools (19.4\%) and those in public schools $(16.4 \%) \quad(p=0.330)$. Even though a higher proportion of urban subjects (18.4\%) were overweight/obese compared to the rural subjects (17.1\%), this difference was also not statistically significant $(p=0.775)$. In addition, Table 1 reveals that the mean BMI $\mathrm{z}$-score was significantly higher for boys than girls $(p<0.001)$. On the contrary, mean triceps skinfold
Table 1 Summary characteristics of the study population by gender

\begin{tabular}{|c|c|c|}
\hline Characteristics & $\begin{array}{l}\text { Boys } \\
N=262\end{array}$ & $\begin{array}{l}\text { Girls } \\
N=260\end{array}$ \\
\hline Age (years) & $9.1(5.0-12.0)$ & $8.9(9.0-12.0)$ \\
\hline Weight (kg) & $30.8(16.4-64.5)$ & $30.8(17.8-59.8)$ \\
\hline Height (cm) & $133.0(104.6-176.1)$ & $132.4(109.2-161.2)$ \\
\hline BMI $\left(\mathrm{kg} / \mathrm{m}^{2}\right)$ & $17.1(13.2-26.3)$ & $17.2(11.6-29.5)$ \\
\hline Triceps skinfold (mm) & $7.6(3.0-23.5)^{\mathrm{a}}$ & $10.2(3.0-24.5)^{\mathrm{a}}$ \\
\hline Weight z-score & $0.22(-2.81-3.60)$ & $0.16(-3.30-3.76)$ \\
\hline Height z-score & $-0.02(-3.73-4.13)$ & $0.05(-3.91-6.19)$ \\
\hline BMI z-score & $0.39(-2.20-2.88)^{b}$ & $0.20(-3.62-3.61)^{b}$ \\
\hline \multicolumn{3}{|l|}{ BMI categories } \\
\hline Severe thinness & $0(0.0)$ & $2(0.8)$ \\
\hline Thinness & $1(0.4)$ & $3(1.2)$ \\
\hline Normal weight & $211(80.5)$ & $211(81.2)$ \\
\hline Overweight & $45(17.2)$ & $33(12.7)$ \\
\hline Obese & $5(1.9)$ & $11(4.2)$ \\
\hline \multicolumn{3}{|l|}{ Type of school } \\
\hline Public & $125(47.7)$ & $129(49.6)$ \\
\hline Private & $137(52.3)$ & $131(50.4)$ \\
\hline \multicolumn{3}{|l|}{ Area of residence } \\
\hline Urban & $182(69.5)$ & $182(70.0)$ \\
\hline Rural & $80(30.5)$ & $78(30.0)$ \\
\hline
\end{tabular}

Values = mean $(\min -\max )$ for continuous variables and $\mathrm{n}(\%)$ for categorized variables

${ }^{\mathrm{a}} p<0.001,{ }^{\mathrm{b}} p<0.05$. BMI categories were defined using WHO criteria [33]

thickness was significantly higher for girls than boys $(p=0.018)$. No significant differences were observed for the other anthropometric variables.

Table 2 shows the associations between the different factors with overweight/obesity as dependent variable. In bivariate analysis, moderate $(>2-4$ times/week $)(p<0.001)$ and high $(>4-7$ times/week $)(p=0.010)$ physical activities were significantly associated with a lower prevalence of overweight/obesity. Also, children in the middle $(p<0.001)$ and high $(p<0.001)$ occupation classes and those with a moderate $(>1-3 \mathrm{~h} /$ day $)(p<0.001)$ and high $(>3-6 \mathrm{~h} /$ day $)(p=0.012)$ sedentary lifestyle were significantly more likely to be overweight/obese compared to those in the low occupation class and those with a low sedentary lifestyle $(\leq 1 \mathrm{~h} /$ day $)$. Children attending private schools had higher odds of being overweight/obese when compared to their peers in public schools. However, this association was not significant. After controlling for age, gender, design variables (school and class) and all significant variables in the bivariate analysis (physical activity, sedentary lifestyle and occupation class), the multivariable analysis indicated that there was a significant independent inverse relationship between physical activity (> $2-4$ times/week) 
Table 2 Prevalence and odds ratios $(95 \% \mathrm{Cl})$ for the association of factors with weight status of school children $(N=522)$

\begin{tabular}{|c|c|c|c|c|c|c|c|c|}
\hline \multirow[t]{2}{*}{ Factors } & \multirow[t]{2}{*}{$\mathrm{N}$} & \multicolumn{7}{|c|}{ Overweight/obesity } \\
\hline & & $\begin{array}{l}\text { Prevalence } \\
(\%)\end{array}$ & $\begin{array}{l}\text { Bivariate } \\
\text { OR }\end{array}$ & $(95 \% \mathrm{Cl})$ & $p$-value ${ }^{a}$ & $\begin{array}{l}\text { Multivariable } \\
\text { OR }\end{array}$ & $(95 \% \mathrm{Cl})$ & $p$-value \\
\hline Physical activity & & & & & $<0.001$ & & & $<0.001$ \\
\hline$\leq 2$ times/week & 209 & 27.8 & Ref. & & & Ref. & & \\
\hline$>2-4$ times/week & 194 & 14.9 & 0.2 & $(0.1-0.3)$ & & 0.1 & $(0.05-0.3)$ & \\
\hline$>4-7$ times/week & 119 & 5.9 & 0.4 & $(0.1-0.8)$ & & 0.2 & $(0.1-0.6)$ & \\
\hline Sedentary lifestyle & & & & & $<0.001$ & & & 0.001 \\
\hline$\leq 1 \mathrm{~h} /$ day & 196 & 11.2 & Ref. & & & Ref. & & \\
\hline$>1-3$ h/day & 203 & 17.2 & 3.1 & $(1.8-5.9)$ & & 3.3 & $(1.8-6.9)$ & \\
\hline$>3-6$ h/day & 123 & 30.1 & 2.0 & $(1.2-3.4)$ & & 2.4 & $(1.2-4.3)$ & \\
\hline Occupation class & & & & & $<0.001$ & & & $<0.001$ \\
\hline Low & 239 & 7.1 & Ref. & & & Ref. & & \\
\hline Middle & 149 & 14.8 & 9.7 & $(5.3-17.9)$ & & 8.6 & $(4.4-16.9)$ & \\
\hline High & 134 & 41.0 & 4.0 & $(2.3-7.1)$ & & 4.3 & $(2.2-8.1)$ & \\
\hline Parental education & & & & & 0.765 & & & \\
\hline Illiterate & 129 & 20.2 & Ref. & & & & & \\
\hline Primary & 107 & 15.9 & 0.8 & $(0.4-1.7)$ & & - & - & - \\
\hline Secondary & 146 & 19.2 & 1.0 & $(0.5-2.0)$ & & - & - & - \\
\hline Higher education & 140 & 16.4 & 0.8 & $(0.4-1.5)$ & & - & - & - \\
\hline Type of school & & & & & 0.330 & & & \\
\hline Public & 254 & 16.4 & Ref. & & & & & \\
\hline Private & 268 & 19.4 & 1.2 & $(0.8-2.0)$ & & - & - & - \\
\hline Area of residence & & & & & 0.774 & & & \\
\hline Rural & 158 & 17.1 & Ref. & & & & & \\
\hline Urban & 364 & 18.4 & 0.9 & $(0.6-1.5)$ & & - & - & - \\
\hline
\end{tabular}

Multivariable odds ratios have been adjusted for age, gender, design variables (school and class), and all significant variables in bivariate analysis $O R$ Odds ratio, $\mathrm{Cl}$ confidence interval. ${ }^{a} p$-value for whole variable significance

$(p<0.001)$ and $>4-7$ times/week $(p=0.010)$ with overweight/obesity. In addition, a significant independent positive association was observed between the high occupation class $(p<0.001)$ and high sedentary lifestyle $(>3-6 \mathrm{~h} /$ day $)$ $(p=0.016)$ with overweight/obesity.

The unadjusted analysis in Table 3 shows the median of triceps skinfold thickness across the different factors. The overall median of triceps skinfold thickness was $8.0 \mathrm{~mm}$. The median triceps skinfold thickness was significantly $(p=0.001)$ higher among children with low physical activity ( $\leq 2$ times/week) compared to those with high physical activity ( $>4-7$ times/week). The factors that had the largest significant relationship with triceps skinfold thickness were sedentary lifestyle and occupation class: children in the high occupation class $(p<0.001)$ and those with a high sedentary lifestyle (> $3-6$ h/day) $(p<0.001)$ had the highest median triceps skinfold thickness of $9.0 \mathrm{~mm}$ compared to $7.0 \mathrm{~mm}$ for those in the low occupation class and those with a low sedentary lifestyle $(\leq 1 \mathrm{~h} /$ day $)$. Also, the children in the urban area and those attending private schools had significantly higher median triceps skinfold thickness compared to their peers in the rural area and those attending public schools.

Table 4 presents the findings of quantile regression estimates of the median of triceps skinfolds with their corresponding standard errors. A significant negative association was observed between high physical activity and triceps skinfold thickness $(p=0.023)$. The factors that had the largest significant relationship with triceps skinfold thickness were sedentary lifestyle: median triceps skinfold thickness of those with high sedentary activity (> $3-6 \mathrm{~h}$ /day) was $1.37 \mathrm{~mm}$ higher than those with a low sedentary activity $(\leq 1 \mathrm{~h} /$ day $)(p=0.029)$; occupation class: those in the high occupation class had a $1.86 \mathrm{~mm}$ higher median triceps skinfold thickness than those from the low occupation class $(p=0.007)$.

The differences in the proportions of physical activity and sedentary lifestyle with respect to occupation class are presented in Table 5 . Both physical activity and 
Table 3 Comparison of median of triceps skinfold thickness of school-age children $(N=522)$

\begin{tabular}{|c|c|c|}
\hline \multirow[t]{2}{*}{ Factors } & \multicolumn{2}{|c|}{ Triceps skinfold (mm) } \\
\hline & Median & $p$-value ${ }^{a}$ \\
\hline Physical activity & & 0.001 \\
\hline$\leq 2$ times/week & 8.0 & \\
\hline$>2-4$ times/week & 7.0 & \\
\hline$>4-7$ times/week & 7.0 & \\
\hline Sedentary lifestyle & & $<0.001$ \\
\hline$\leq 1$ h/day & 7.0 & \\
\hline$>1-3$ h/day & 8.0 & \\
\hline$>3-6$ h/day & 9.0 & \\
\hline Occupation class & & $<0.001$ \\
\hline Low & 7.0 & \\
\hline Middle & 8.0 & \\
\hline High & 9.0 & \\
\hline Parental education & & 0.625 \\
\hline Illiterate & 7.8 & \\
\hline Primary & 8.0 & \\
\hline Secondary & 8.0 & \\
\hline Higher education & 7.8 & \\
\hline Type of school & & 0.008 \\
\hline Public & 7.0 & \\
\hline Private & 8.0 & \\
\hline Area of residence & & 0.045 \\
\hline Rural & 7.3 & \\
\hline Urban & 8.0 & \\
\hline
\end{tabular}

Kruskal-Wallis test used to compare median triceps skinfolds across all groups. The 10th and 90th percentiles of triceps skinfold of all study participants were 3.6 and $16.0 \mathrm{~mm}$ respectively

sedentary lifestyle were significantly associated with occupation class. Also, low physical activity ( $\leq 2$ times/week) and high sedentary lifestyle (> $3-6 \mathrm{~h}$ /day) were more common among children in the high occupation class. On the contrary, high physical activity ( $>4-7$ times/week) and low sedentary lifestyle ( $\leq 1 \mathrm{~h} /$ day) were more common among children in the low occupation class.

\section{Discussion}

This study describes out of school physical activity and sedentary lifestyle of Cameroonian school-age children for the first time. The purpose of the study was to investigate whether there are relationships between out of school physical activity, sedentary lifestyle and socioeconomic status indicators with weight status and adiposity of school children after adjusting for different variables.

This study found that physical activity ( $>2$ times/week) had an independent inverse relationship with overweight/ obesity and triceps skinfold thickness. Physical activity had a similar relationship with BMI-defined overweight/
Table 4 Multiple quantile regression estimates of the median of triceps skinfold thickness of school children $(N=522)$

\begin{tabular}{|c|c|c|c|}
\hline \multirow[t]{2}{*}{ Factors } & \multicolumn{3}{|l|}{ Median } \\
\hline & Estimate & SE & $p$-value \\
\hline Intercept & 5.61 & 1.02 & $<0.001$ \\
\hline \multicolumn{4}{|l|}{ Physical activity } \\
\hline$\leq 2$ times/week & 0 & - & - \\
\hline$>2-4$ times/week & -1.16 & 0.59 & 0.044 \\
\hline$>4-7$ times/week & -1.36 & 0.60 & 0.023 \\
\hline \multicolumn{4}{|l|}{ Sedentary lifestyle } \\
\hline$\leq 1 \mathrm{~h} /$ day & 0 & - & - \\
\hline$>1-3$ h/day & 1.22 & 0.44 & 0.006 \\
\hline$>3-6$ h/day & 1.37 & 0.62 & 0.029 \\
\hline \multicolumn{4}{|l|}{ Occupation class } \\
\hline Low & 0 & - & - \\
\hline Middle & 0.57 & 0.47 & 0.224 \\
\hline High & 1.86 & 0.68 & 0.007 \\
\hline \multicolumn{4}{|l|}{ Parental education } \\
\hline Illiterate & 0 & - & - \\
\hline Primary & 0.34 & 0.68 & 0.619 \\
\hline Secondary & 0.34 & 0.58 & 0.559 \\
\hline Higher education & -0.16 & 0.63 & 0.795 \\
\hline \multicolumn{4}{|l|}{ Type of school } \\
\hline Public & 0 & - & - \\
\hline Private & 0.06 & 0.71 & 0.929 \\
\hline \multicolumn{4}{|l|}{ Area of residence } \\
\hline Rural & 0 & - & - \\
\hline Urban & -1.16 & 0.63 & 0.07 \\
\hline
\end{tabular}

SE standard error. Age, gender and all factors were included in the quantile regression analysis. The estimate associated with each category is the difference in triceps skinfold thickness compared to the reference category

obesity in a sample of Pakistani primary school children [29]. Children in our study exhibiting low physical activity had significantly higher median triceps skinfold thickness compared to those with high physical activity. A report indicated that children who were moderately active were at risk of accumulating excess body fat compared to those who were active [35]. Also, a recent US study revealed that children who did not meet the physical activity guidelines were at risk of being overweight/obese [36]. It is a wellknown fact that energy expenditure in children is increased when they are involved in physical activity, and apart from reducing the risk of overweight/obesity [8], it could also lead to a favorable body composition. However, a study in Nigeria did not record any association between physical activity and BMI [37]. In the Nigerian study, there could have been recall bias because physical activity was self-reported by the children and also, the study had a small number of overweight/obese participants. In our 
Table 5 The association of physical activity and sedentary lifestyle with occupation class $(\mathrm{N}=522)$

\begin{tabular}{|c|c|c|c|c|c|c|c|}
\hline & \multicolumn{6}{|c|}{ Occupation class [\%(95\% Cl)] } & \multirow[t]{2}{*}{$p$-value ${ }^{a}$} \\
\hline & Low & & Middle & & High & & \\
\hline \multicolumn{8}{|l|}{ Physical activity } \\
\hline$\leq 2$ times/week & 37.2 & $(31.4-43.5)$ & 38.9 & $(31.5-46.9)$ & 46.3 & $(38.1-54.7)$ & 0.016 \\
\hline$>2-4$ times/week & 35.1 & $(29.4-41.4)$ & 40.3 & $(32.7-48.3)$ & 37.3 & $(29.6-45.8)$ & \\
\hline$>4-7$ times/week & 27.6 & $(22.3-33.6)$ & 20.8 & $(15.1-28.0)$ & 16.4 & $(11.1-23.6)$ & \\
\hline \multicolumn{8}{|l|}{ Sedentary lifestyle } \\
\hline$\leq 1 \mathrm{~h} /$ day & 43.1 & $(37.0-49.4)$ & 38.9 & $(31.5-46.9)$ & 26.1 & $(19.4-34.2)$ & 0.001 \\
\hline$>1-3$ h/day & 36.8 & $(30.9-43.1)$ & 39.6 & $(32.1-47.6)$ & 41.8 & $(33.8-50.2)$ & \\
\hline$>3-6 \mathrm{~h} /$ day & 20.1 & $(15.5-25.6)$ & 21.5 & $(15.6-28.7)$ & 32.1 & $(24.8-40.4)$ & \\
\hline
\end{tabular}

${ }^{a}$ Chi square test. $\mathrm{Cl}$ confidence interval

study, physical activity was reported by parents, and we cannot rule out the possibility of recall bias. However, this was limited by asking children to hand in the questionnaires only to their parents/guardians (who are presumed to be most familiar with the children and have a higher ability to recall their activity levels) to complete the questionnaires.

In the current study population, out of school sedentary lifestyle and occupation class were also independent predictors of overweight/obesity after controlling for age, gender, design variables and all variables that were significant in the bivariate analysis. When all the variables in the unadjusted analysis plus age and gender were included in quantile regression analysis, sedentary lifestyle and occupation class had the largest significant relationships with triceps skinfold thickness. A report on English children showed a positive association between sedentary behavior (which was questionnaire-based) and BMI. However, the authors observed no association between objectively measured sedentary behavior and BMI [38]. Also, a recent Cameroon study indicated that SES was significantly associated with BMI-defined overweight/obesity and central obesity in children [39]. A recent systematic review associated objectively and subjectively measured sedentary activities to unfavorable body composition [40]. The associations observed in our study could be explained by the fact that in Cameroon, high income earners can easily afford for items that, could contribute to a sedentary lifestyle to some extent like a TV set, computer and motorization to and from school. These items are readily available in urban than rural settings. During the study period, it was also observed that these items are common in private schools where fees are higher than public schools. Most children in some private schools in urban settings use bus services to school and spend their play time in school watching TV and these, to an extent, contribute to higher levels of sedentary lifestyle. However, we did not examine the independent contribution of these aspects to sedentary lifestyle. These children in private schools can therefore accumulate more body fat as a report had confirmed that children attending private schools had higher odds of not meeting physical activity guidelines [41].

This study has also shown that sedentary lifestyle and physical activity were associated with occupation class. A higher proportion of children with low physical activity and high sedentary lifestyle were in the high occupation class, while a higher proportion of children with high physical activity and low sedentary lifestyle were in the low occupation class. In Cameroon, low income earners and those in rural settings are usually involved in more long distance walking and they carry out high intensity activities like farming, which extends to children. Also, available data in Cameroon shows that daily energy expenditure is higher among rural subjects that urban subjects [5]. A report had associated sedentary lifestyle with living in an urban setting and high income background [42].

Parental level of education was not significantly associated with overweight/obesity in the bivariate analysis. Matsudo et al. [41] reported a similar observation among Brazilian children. Education level does not seem to be a good indicator of socioeconomic status in Cameroon as being educated does not assure a better remuneration as indicated in a previous study [32]. However, a significant inverse association between parental level of education and overweight/obesity was recorded in a US study [43]. The area of residence (rural and urban) and type of school (public and private) were not associated with overweight/obesity in our study. However, a recent systematic review revealed that urban residence may be positively associated with overweight/ obesity in Sub-Saharan Africa [44]. Also, a study in Kenya (which included a convenient sample of school children) indicated that children attending private schools had higher odds of being overweight/obese [25]. These inconsistencies may be explained by small sample sizes of studies and differences in sampling procedures.

Our study had limitations worth mentioning. This study presents results of out of school physical activity 
levels in children, which were not assessed with respect to physical activity domains. For instance, when school hours was included in a recent report as one of the domains of objectively measured physical activity, it contributed to 55 and $46 \%$ of total sedentary and moderate-to-vigorous physical activity respectively [45]. The sample of children was not nationally representative and causal relationships cannot be established using a cross sectional design. It was also not possible to control for the confounding effect of puberty. In addition, parental occupation class was established using the Cameroon government classification system, which may not be similar to that of the private service. Further, the findings of this study should be interpreted with caution because calorie intake, which is an important determinant of body weight, was not assessed. A WHO report had indicated that the evidence showing a positive association between overweigh/obesity and the consumption of energy dense foods poor in micronutrients is convincing [46]. Other studies have indicated the association of low intakes of fruits and vegetables, large portion sizes [47] and high consumption of sugar-sweetened beverages [48] with changes in weight. But it is still a debate if reducing intake of sugar-sweetened beverages can lead to weight loss [49]. These suggest that the associations observed in this study could change if dietary intake and eating habits are included in the multivariable models.

Despite the above limitations, this study presents data on out of school physical activity, sedentary lifestyle and adiposity measured using triceps skinfold thickness among school children for the first time in Cameroon. The use of quantile regression in the analysis allowed us to determine the effect of the different factors on the median of triceps skinfold thickness. Even though the study uses proxy reporting, a review had indicated that proxy measures can predict physical activity levels in children [50] and may also complement objective measurements because they can provide information on the type of physical activity [44]. The data sets the basis for future studies, especially with initiatives aimed at establishing and validating an instrument that can be used to assess physical activity and sedentary lifestyle of children in our setting.

\section{Conclusion}

This study has shown an inverse relationship between physical activity and overweight/obesity. It also shows that sedentary lifestyle and occupation class were positively associated with overweight/obesity and had the largest significant relationship with triceps skinfold thickness.

In order to understand the activity patterns of children in our setting, domain-specific physical activity and sedentary lifestyle need to be assessed objectively and subjectively, in and out of school. Also longitudinal studies are warranted to understand the influence of environmental, cultural and behavioral drivers of physical activity and sedentary lifestyle in our multiethnic setting, where fatness is still being regarded as a sign of good health and wellbeing. In addition, the school environment can significantly influence the development of obesity if renovations or adjustments are made to provide not just nutrition education, but also opportunities for physical activity and enough time for physical education especially in urban-private schools.

\section{Abbreviations}

BMI: Body mass index; NWR: North West Region; TV: Television; WHO: World Health Organization

\section{Acknowledgements}

This study was conducted by the Nutrition and Health Research Group (NHRG), Bamenda - Cameroon. Also, the authors are grateful to the administration of the schools, children and parents for accepting to participate in this study.

Funding

The authors funded the study.

\section{Availability of data and materials}

The datasets used and/or analyzed during the current study are available from the corresponding author on reasonable request.

\section{Authors contributions}

LKN was responsible for the conception and design of the study, direct collection of data and processing, statistical analysis and drafting of the manuscript. MBSA contributed to the conception and design of the study as well as interpretation and analysis concepts of the data. LLN contributed to the conception and design of the study, participated in data collection, as well as interpretation of data and drafting of manuscript. All authors revised the manuscript and gave a final approval of the submitted version.

\section{Ethics approval and consent to participate}

Ethical approval for this study was obtained from the institutional review board of the Catholic University of Cameroon (CATUC), Bamenda.

Administrative clearances were obtained from the North West regional delegations for basic education and public health. All head teachers and parents/guardians gave written informed consent before the study commenced. Verbal assent was also obtained from each child before any study related procedure was carried out.

\section{Consent for publication}

Not applicable.

\section{Competing interests}

The authors declare that they have no competing interests.

\section{Publisher's Note}

Springer Nature remains neutral with regard to jurisdictional claims in published maps and institutional affiliations.

\section{Author details}

'Department of Biochemistry, Catholic University of Cameroon (CATUC), Bamenda, P.O. Box 782, Bamenda, Cameroon. 'Nutrition and Health Research Group (NHRG), Bamenda, Cameroon. ${ }^{3}$ Department of Nursing and Midwifery, University of Bamenda, P.O. Box 39, Bambili, Bamenda, Cameroon. 
Received: 12 April 2017 Accepted: 31 October 2017

Published online: 07 November 2017

\section{References}

1. World Health Organization. Obesity: preventing and managing the global epidemic. In: WHO technical report series number 894. Geneva; 2000.

2. Han JC, Lawlor DA, Kim SY. Childhood obesity. Lancet. 2010;373:1737-48.

3. Karnik S, Kaneka A. Childhood obesity: a global public health crisis. In J Pre Med. 2012:3:1-7.

4. Lobstein T, Baur L, Uauy R. Obesity in children and young people: a crisis in public health. Obes Rev. 2004;5(suppl. 1):4-85.

5. Assah FK, Mbanya JC, Ekelund ULF, Wareham NJ, Brage S. Urbanization, physical activity and metabolic health in sub-Saharan Africa. Diabetes Care. 2011;34:491-6

6. World Health Organization. Global health risks: mortality and burden of disease attributable to selected major risks. Geneva: WHO; 2009.

7. Tremblay MS, Colley RC, Saunders TJ, Healy GN, Owen N. Physiological and health implications of a sedentary lifestyle. Appl Physiol Nutr Metab. 2010;35:725-40.

8. Poitras VJ, Gray CE, Borghese MM, Carson V, Chaput JP, et al. Systematic review of the relationships between objectively measured physical activity and health indicators in school-aged children and youth. Appl Physiol Nutr Metab. 2016:41:S197-239.

9. Janssen I, Leblanc AG. Systematic review of health benefits of physical activity and fitness in school-age children and youth. Int Behav Nutr Phys Act. 2010;7:40

10. Telama R, Yaong X, Viikari J. Physical activity from childhood to adulthood: a 21-year tracking study. Am J Prev Med. 2005;28:267-73.

11. Berkey C, Rockett H, Gillman M, Colditz G. One year change in activity and inactivity among 10 - 15 year old boys and girls: relationship to change in body mass index. Pediatrics. 2003;11(4):836-43.

12. Trost SG, Sirard JR, Dowda M, Pfeiffer KA, Pate RR. Physical activity in overweight and non-overweight pre-school children. Int J Obes. 2003;27(7):834-9.

13. Mo-suwan L, Tongkumchum $P$, Puetpaiboon A. Determinants of overweight tracking from childhood to adolescence: a 5 year follow-up of Hat Yai school children. Int J Obes. 2000;24:1642-7.

14. Must A, Tybor DJ. Physical activity and sedentary behavior: a review of longitudinal studies of weight and adiposity in youth. Int J Obes. 2005;29(Suppl 2):84-96.

15. Biddle SJH, Bengoechea EG, Weisner G. Sedentary behavior and adiposity in youth: a systematic review of reviews and analysis of causality. Int J Behav Nutr Phys Act. 2017;14:43.

16. Ferrari GL, Araujo TL, Oliveira LC, Matsudo V, Fisgerb M. Association between electronic equipment in the bedroom and sedentary lifestyle, physical activity and body mass index of children. J Pediatr. 2015;91:574-82.

17. Greca JP, Silva DA, Loch MR. Physical activity and screen time in children and adolescents in medium size town in south of Brazil. Rev Paul Pediatr. 2016:34(3):316-22.

18. Carson V, Hunter S, Kuzik N, Gray CE, Poitras VJ. Systematic review of sedentary behavior and health indicators in school-age children and youth: an update. Appl Physiol Nutr Metab. 2016;41:S240-65.

19. Burke V, Beilin LT, Durkin K, Stritzke WG, Houghton S, et al. Television, computer use, physical activity, diet and fitness in Australian adolescents. Int J Pediatr Obes. 2006;1:248-55.

20. Peltzer K. Health behavior and protective factors among school children in four African countries. Int J Behav Med. 2009;16:172-80.

21. Bénéfice $E$, Garnier D, Ndiaye G. Assessment of physical activity among rural Senegalese adolescent girls: influence of age, sexual maturation and body composition. J Adolesc Health. 2001:28:319-27.

22. Micklesfield LK, Pedro TM, Kahn K, Kinsman J, Pettifor JM, et al. Physical activity and sedentary behavior among adolescents in rural South Africa: levels, patterns and correlates. BMC Public Health. 2014;14:40.

23. Joens-Matre RR, Welk GJ, Calabro MA, Russell DW, Nicklay E, et al. Rural-urban differences in physical activity, physical fitness and overweight prevalence of children. J Rural Health. 2008;24(1):49-54.

24. Orhan $\mathrm{O}$. The relationship between physical activity level, body mass index and body fat percentage in urban and rural elementary school students. Educ Res Rev. 2015;10(1):67-74

25. Mathuri SK, Wachira LI, Onywera VO, Tremblay MS. Correlates of objectively measured overweight/obesity and physical activity in Kenyan school children: results from ISCOLE-Kenya. BMC Public Health. 2014;14:436.
26. Hall DM, Cole TJ. What is the BMI? Arch Dis Child. 2006;91:283-6.

27. McCarthy HD. Body fat measurements in children as predictors for the metabolic syndrome: focus on waist circumference. Proc Nutr Soc. 2006:65:385-92.

28. Schmelzle HR, Fush C. Body fat in neonates and young infants: validation of skinfold thickness versus dual-energy X-ray absorptiometry. Am J Clin Nutr. 2002:76:1096-100

29. Mushtaq MU, Gull S, Mushtaq K, Shahid U, Shad MA, et al. Dietary behaviors, physical activity and sedentary lifestyle associated with overweight and obesity, and their socio-demographic correlates, among Pakistani primary school children. Int J Behav Nutr Phys Act. 2011:8:130.

30. US Department of Health and Human Sciences. Healthy people 2010 2nd ed. Washington, DC; 2000

31. American Academy of Pediatrics CoPE. Children, adolescents and television. Pediatrics. 2001;107:423-6.

32. Fezeu L, Minkoulou E, Balkau B, Kengne AP, Unwin N, et al. Association between socioeconomic status and adiposity in urban Cameroon. Int J Epidemiol. 2005:35:105-11.

33. de Onis M, Onyango AW, Borghi E, Siytam A, Nishida C, et al. Development of a WHO growth reference for school-aged children and adolescents. Bull World Health Organ. 2007;85:660-7.

34. Koenker R. Quantile regression in R: a vignette, 2017 version. Available from https://cran.r-project.org/web/packages/quantreg/vignettes/rq.pdf. Accessed 15 July 2017.

35. Straatmann VS, da Veiga GV. Cardiorespiratory fitness, physical activity and indicators of adiposity in Brazilian adolescents. Hum Mov. 2015:16(2):64-70.

36. Bai Y, Chen S, Laurson KR, Kim Y, Saint-Maurice PF, et al. The associations of youth physical activity and screen time with fatness and fitness: the 2012 NHANES National Youth Fitness Survey. PLoS One. 2016;11(1):e0148038.

37. Senbanjo IO, Oshikoya KA. Physical activity and body mass index of schoo children and adolescents in Abeokuta, Southwest Nigeria. World J Pediatr. 2010;6(3):217-22.

38. Coombs NA, Stamatakis E. Associations between objectively assessed and questionnaire-based sedentary behavior with BMI-defined obesity among general population children and adolescents living in England. BMJ Open. 2015;5:e007172

39. Navti LK, Ferrari U, Tange E, Bechtold-Dalla Pozza S, Parhofer KG. Contribution of socioeconomic status, stature and birth weight to obesity in sub-Saharan Africa: cross sectional data from primary school-age children in Cameroon. BMC Public Health. 2014;14:320.

40. Carson V, Hunter S, Kuzik N, Gray CE, Poitras VJ, et al. Systematic review of sedentary behavior and health indicators in school-age children and youth: an update. Appl Physiol Nutr Metab. 2016;41:S240-65.

41. Matsudo VK, Ferrari GL, Araujo, Oliveira L, Mirec E, et al. Socioeconomic status indicators, physical activity, and overweight/obesity in Brazilian children. Rev Paul Pediatr. 2016:34(2):162-70.

42. Gomez LF, Parra DC, Lobelo F, et al. Television viewing and its association with overweight in Colombian children: results from the 2005 National Nutrition Survey: a cross sectional study. Int J Behav Nutr Phys Act. 2007;4:41.

43. Ogden CL, Lamb MM, Carroll MD, Flegal KM. Obesity and socioeconomic status in children and adolescents: United States, 2005 - 2008. NCHS Data Brief. 2010;51:1-8

44. Muthuri SK, Francis CE, Wachira LM, LeBlanc AG, Sampson M, et al. Evidence of an overweight/obesity transition among school-aged children and youth in sub-Saharan Africa: a systematic review. PLoS One. 2014:9(3):e92846.

45. Sprengeler O, Wirsik N, Hebestreit A, Herrmann D, Ahrens W. Domain-specific self-reported and objectively measured physical activity in children. Int J Environ Res Public Health. 2017;14:242

46. World Health Organization. Diet, nutrition and prevention of chronic diseases. Report of a joint WHO/FAO expert consultation. In: WHO technical report series no. 916: 61; 2003.

47. Drewnowski A, Damon N. The economics of obesity, dietary energy density and energy cost. Am J Clin Nutr. 2005;82:265S-73S.

48. Malik VS, Schulze MB, Hu FB. Intake of sugar-sweetened beverages and weight gain: a systematic review. Am J Clin Nutr. 2006:84(2):274-88.

49. Allison DB, Mattes RD. Nutritively sweetened beverage consumption and obesity. The need for a solid evidence on a fluid issue. JAMA. 2009;301:318-20.

50. Kohl HW, Fulton JE, Caspersen CJ. Assessment of physical activity among children and adolescents: a review and synthesis. Prev Med. 2000;31:S54-76. 